\title{
Study on the Optimization of Library Information Management of Colleges in New Era
}

\author{
Xiuhua Ma \\ Library, Jilin Agricultural University, Changchun, 130118 \\ 3259024068@qq.com
}

Keywords: New Era; Colleges; Library management; Management mode

\begin{abstract}
Colleges are important places to train high-quality talents, and main ways to spread knowledge. In the network era, soaring colleges are gradually building digital libraries and are taking advantage of network platform to provide electronic information resources such as periodicals and electronic books. Facing a huge digital library and information resources and a wide array of information, colleges have to innovate the management mode of library and information management, improve the professional quality of librarians, to provide orderly service for students and teachers. Exploring the management mode of library and information management mode in the new era, and promoting the sustainable development of colleges' library and information management are main topics in this paper.
\end{abstract}

\section{Introduction}

All along, the College's main responsibility is to develop high level and high quality talents, which asks higher requirement on the library and information management mode. The economic time has already come and digital network has gradually become the main trend of social development. While facing complex and disordered information, the information mode will affect the learning and research activities especially for college students and teachers, which will bring about interferences. Therefore, management personnel of library information have to change the traditional management mode, resolve the crisis, scientifically manage library information and create a new path of management in the network era.

\section{Current Condition of Library Information Management in Colleges}

Current Condition of Traditional Library Information Management. Books and information have different concepts, but both belong to information, and colleges almost use same equipment, procedure and management mode. In colleges, while carrying out management, library information management personnel collect information, arrange target index, arrange shelves, retrieve and utilize and all the actions are carried out in the library or on the shelves. Traditional library information management separately manages books and information and relevant departments do not regularly connect with each other. When teachers and students need to search for information, they have to search in different areas which will bring about inconvenience and they cannot have complete information. In addition, sometimes, repeated information will also cause interference and waste time.

Current Condition of Library Information Management in the New Era. Along with the development of network, many colleges have already build digital library and electronic information network, which is convenient for both students and teachers to search for information and is able to save time. However, the information resources are unlimited without filter and code, and they are not organized. As a result, it is difficult to get the information, which will contribute difficulties to carry out research. In reality, digital library and information checking library have repeated information in terms of contents and classification. Sometimes, some contents are in the digital library website and information website, so cross information will mislead students and they are not able to classify it. What's more, they have to log on simultaneously and some websites managers will put some information in the database without checking in order to have more reviews 
and it is impossible to avoid repeated information in this case. In addition, concerning library information management mode, they are divided into different departments with different modes. Even though they have a lot of similar information, they still adopt different management modes, which will cause different opinions and it will be difficult to integrate resources without a unified standard.

\section{The Positioning of Library Information Management Mode in the New Era}

In the new era of information network, library information management takes knowledge management mode as the focus. Only by correctly position the knowledge mode, can we fully play the role of library information management, which is an important topic and a necessary path.

Firstly, standardize core business knowledge, that is to say we have to standardize and systematically operate library information management and realize its automation. It won't ask higher requirement on employees such as creative thinking ability because they are able to collect information, organize and send messages and carry out regulated operation. Based on this, we can effectively save costs and unify library information management.

Secondly, innovate a professional knowledge management mode. The goal to manage library information and innovate management mode is to help students and teachers to find valuable information in the huge information ocean, which is also the impetus to develop library information. Therefore, relevant library information departments should have professional managers and colleges should adopt incentive policies to keep and attract talents to encourage them carry out valuable work. In addition, library information departments should also carry out regular training for key managers to make them fully play their role. Through these talents, we can sustainability develop library information management work.

Thirdly, adhere to the principle of total optimum and innovate the business integration management mode, which is trans-department and trans-agencies, and can carry out communications fluently. By adopting business integration, we can integrate resources from different departments and agencies to create unified standard and realize resource sharing. What's more, we can timely give feedback and the operation policies aim to realize overall optimum. Furthermore, these management mode can also help to save costs and make it convenient for users to check information and avoid repeated information.

Fourthly, establish learning-oriented library information organization. When the information is continually expanding, people who can understand the most advanced knowledge are able to shine out in competition and keep pace with time or they will fail without keeping pace with time. Whether library information management can work perfectly, keep pace with the time, and sustainably develop depend on learners, which ask the library information department to innovate the learning mode and adopt library information to solve problems. What's more, encouraging employees to participate together and realize resource sharing to integrate individual benefits and collective benefits, realize innovation, improve employee's innovative ability, perfect management mode, make it flexible, satisfy the needs of audience is urgent.

\section{Countermeasures to Innovate the Library Information Management Mode in Colleges}

Innovate the Integrated Management Mode for Library Information. An integrated management mode is to effectively integrate library resources and information resources into one system based on unified management methods and standards so as to realize a comprehensive management. This kind of management mode is able to classify library and information resources based on a unified system, which can let students search separately and is integrated. Various colleges can integrate into national library and add their resources to improve the integrity of library information. In addition, various colleges can inform students of a perfect information management mode and communicate with other colleges and refer to excellent ones so as to share information and realize integrated construction. 
Construct a Library Information Network Platform. The soaring number of network brings new opportunities for library information development and we can perfectly integrate resources based on establishing a network platform and put them online. In addition, along with the development of remote technology, library information can take advantage of it to combine information resources and scientific technology to realize scientific and high efficient management. On the library information platform, students can upload advanced knowledge, but network managers have to check the information and improve students' enthusiasm and realize resource sharing. Concerning repeated information, we can combine digital library and information library, integrate the contents in the data base and delete same library resources. Furthermore, we can also perfect the information and library sharing system, so that students timely share information organized on academic forum so as to promote knowledge dissemination. By the way, colleges should improve computer network utilization and improve transmission level and optimize database.

Introduce and Cultivate Professional Management Talents. To innovate college library information management, we cannot get rid of professional management talents. On the one hand, we can introduce talents and improve enrollment standards to let them have computer certificate and operation experience, play a role in departments and improve the profession. In addition, colleges can communicate with relevant information management department to purchase advanced library information management software and invite professional staffs to try the software and innovate. Furthermore, colleges can also carry out training for current managers and improve the professional quality as well as service to improve their ability to use computers and provide better service for teachers and students.

Strengthen the Connection Among Colleges and Enterprises. To realize the information resource sharing among different colleges and enterprises will provide a wider channel for teachers and students which can also strengthen learning and communication. The scientific research in colleges is one of the ways to explore knowledge and the cooperation among different colleges can contribute to helping students and teachers to acquire diverse knowledge and the resource sharing is convenient for teachers and students to search. In addition, in the process of producing, we will meet problems of different skills, which includes valuable information for research. Besides, college and enterprise cooperation can broaden the channels to carry out research activities and enrich contents, and help enterprises to solve problems. The methods for cooperation include following aspects: after the negotiation of college leaders and mangers of other departments, we can share the library information system, improve the utilization rate and range of database. While referring to the management experience and techniques of other colleges, some colleges lag behind and improve themselves. What's more, after getting the agreement of college faculties and students, and ensuring the safety, we can encourage them to carry out practice in enterprises and apply knowledge into practice. Based on this, we can improve our ability to research and solve problems.

\section{Conclusion}

All in all, in the new era, to innovate the library information management mode, we have to adapt to the needs of times and take advantage of information technology, establish unified library information mechanism and system; establish network resource sharing platform, introduce professional managers, strengthen the connection between colleges and enterprises; take advantage of modern techniques and improve the library information management level.

\section{References}

[1] Fangjing. Humanistic Management- New thoughts for library information management in the new era [J] Journal of Library and Information Sciences in Agriculture, 2009(06) 
[2] Huang Xiaoyan. Analysis on the supply chain management of college libraries-take the library of Shanghai Dianji University as an example [J] Academic Library and Information Service, 2013(09)

[3] Guo Qiuxia. Study on the information service work of college library information management in new era [J] Wireless Internet Technique,2014(07)

[4] Tao Xiumin. Soft Management: New concepts of reader management [J] Journal of Academic Library and Information Science,2014(21)

[5] Liu Zhiyong. Brief talk on the change of college library information management, 2015(7):2620-2621.

[6] Zhao Yaxin. Study on the requirement of library users in Micro - information environment [J] Library and Information Service, 2013(8):17-21; 39.

[7] Xue Jinling. Discuss on the integrated management of library information and archives [J] Documentation \& Information Management for Science and Technology, 2012(1):57-60.

[8] Hu Ping. Discuss on the continuous learning of library information managerial personnel [J]. Journal of Jiamusi Education Institute, 2011, 02.

[9] Cai Shuguang. From information management to knowledge management - a necessary path to play the socil role of library in the new era $[\mathrm{J}] .2005,05$.

[10] Shi Ruilai. College library information and archives should adopt integrated management [J]. Inner Mongolia Agricultural University Library2007,10

[11]Hu Changping, Cao Ning, Luo Xianchun. Discuss on the organizational change of library information in the network environment [J]. Library Tribune, 2005.

[12]Guo Shufen. The Sustainable management and service mode of library information agency-knowledge management Service[J].Lanzhou Journal, 2004 